\title{
The use of pressure monitoring to standardize fetal arterial visualization
}

\author{
Hashem Shemshadi MD, Rod J Rohrich MD FACS, Li Li MD, Jack B Robinson Jr PhD \\ Division of Plastic Surgery, Department of Surgery, The University of Texas \\ Southwestern Medical Center at Dallas, Dallas, Texas
}

H Shemshadi, RJ Rohrich, L Li, JB Robinson Jr. The use of pressure monitoring to standardize fetal arterial visualization. Can J Plast Surg 1996;4(3):161-164. The application of a new x-ray opaque postmortem perfusion system for the visualization of vascular structures in fetal models is presented. This new system allows pig fetus perfusion to be performed at pressures of less than $30 \mathrm{mmHg}$. At higher pressures, extravasations were observed in known weak spots in the fetal vasculature, and multiple perfusions at the same pressure exhibited similar patterns of extravasation (demonstrated at all pressures studied). Therefore this technique is controllable and predictable. It will allow determination of fetal vascular malformations which have been implicated as causes of many birth defects.

Key Words: Anatomy, Birth detects, Fetus, Perfusion, Vasculature

\section{Recours à la surveillance de la tension pour normaliser la visualisation artérielle fotale}

RÉSUMÉ : L'application d'un nouveau système de perfusion post-mortem radio-opaque pour la visualisation des structures vasculaires dans des modèles fœtaux est présentée ici. Le nouveau système permet d'effectuer des perfusions chez des porcelets à des pressions de moins de $30 \mathrm{~mm} \mathrm{Hg}$. À des pressions plus élevées, on observait de l'extravasation en certains points faibles connus de l'appareil vasculaire fœtal et les multiples perfusions à la même pression présentaient des modes similaires d'extravasation (démontrés à toutes les pressions étudiées). Par conséquent, cette technique peut être contrôlée et prévisible. Elle permet la détermination des malformations vasculaires fœtales incriminées dans de nombreuses anomalies congénitales.

Fetal anatomical vasculature has been extensively studied with respect to the differences in developmental stages (1), patterns of branches, number of branches and anatomical weak points (2). With the recent advances in fetal reconstructive surgery (3), one must not only have basic knowledge of fetal anatomy but must also correlate such knowledge with the physiological changes and pressure tolerances of the fetal vascular system before performing a surgical procedure aimed at correcting an intrauterine anomaly.

This study attempted to standardize a method of fetal arterial vascularization at different perfusion pressures and observe any vascular extravasations that may have been caused by increases in perfusion pressure and that are not present in the intact fetus, and to visualize what points of the fetal vascular anatomy are most susceptible to this 
procedure. This provides a method by which dependable and reproducible perfusions can be performed and fetal anatomy can be studied to minimize artefacts induced by the pressure of the perfusion techniques.

\section{BIOLOGY AND MANAGEMENT OF THE FETUS}

A review of the patterns of fetal-maternal circulation reveals that disruption and/or interruption of normal fetal vasculature is a significant factor in dysmorphic structure (4). This affects the normal pattern of arterialization and circulation in the fetus. As the fetus undergoes changes during development, its vascular network undergoes corresponding changes. Changes are seen in the diameter and thickness of the vessel walls (5). Because the intravillous vascular network of the placenta connects with the umbilical-allantoic vessels at three weeks, any pressure changes within the placenta (maternal) may directly influence the umbilical vascular pressure (fetal vascular network) (4).

Pressure changes induced in the uterine-placenta-fetus complex are well known $(6,7)$. As the intervillous bloodflow decreases, the fetal bloodflow decreases because of a reduction in total blood volume. As well the release of catecholamines and sympathetic activation aggravates such flow reduction. Such altered hemodynamic bloodflow leads to rapid fetal injury and destruction of developing neovasculatures, causing vascular ruptures. Changes in laboratory animals have been observed as pressure to the uterineplacenta-fetus complex is changed (8-10). Sudden pressure increases create hemorrhage in the cerebral vasculature, peritoneal cavity and pericardial cavity, leading to cardiac tamponade.

The anatomical vasculature point most susceptible to such derangement is the brain. Derangement takes place mostly in the area of the subependymal matrix below the lateral ventricles in fetuses of less than 35 weeks of gestation and predominately in the cortex of the brain after 36 weeks' gestation $(11,12)$.

\section{ANIMALS AND METHODS}

The perfusion reagent, a lead oxide dispersion stabilized by an oil-detergent emulsion, was prepared as described earlier (13) (Table 1) and $1 \mathrm{~mL}$ was measured out. The sample was then diluted with warm normal saline to achieve a specific gravity in the range of 1.8 to $2 \mathrm{~g} / \mathrm{mL}$. The perfusion was performed by cannulation of the fetus and attachment of a first syringe of saline, for flushing the clots, and followed by a second syringe containing perfusion reagent. Thirty-one porcine fetuses, 10 to $15 \mathrm{~cm}$ (crown to rump length), were perfused through the umbilical artery. Alternate routes of administration, such as the aorta or the carotid, iliac or intracardiac arteries, were used if the umbilical route was not feasible. Initial flushing was done with $4 \mathrm{~mL}$ warm saline (twice the animal's total circulating blood volume). This was achieved with the use of a $23 \mathrm{G}$ angiocatheter. Efflux of saline from the opposite umbilical artery insured the absence of any possible clot and a correct anatomical site for the catheter. Subsequently, $4 \mathrm{~mL}$ of warm contrast material was injected manually at a predetermined injection pressure with the aid of a pressure manometer. Eight different pressures were studied (Table 2). Radiographs were made on mammographic x-ray film, for better resolution of 
fine detail. Fetuses were originally purchased from Pelfreez (Arkansas) and were perfused within $24 \mathrm{~h}$ postmortem. Transport and storage were on ice. Whenever possible, each pressure point was tested with litter mates to limit variability.

TABLE 1: Components of fetal vascular perfusion reagent

$\begin{array}{lc}\text { Component } & \text { Amount } \\ \text { Water } & 9 \mathrm{~mL} \\ \text { Tris buffer, 1 molar, } & 1 \mathrm{~mL} \\ \text { pH } 7.3 & 2 \mathrm{~mL} \\ \text { Mineral oil } & 0.2 \mathrm{~mL} \\ \text { Triton X-100 } & 2 \mathrm{drops} \\ \text { Antifoam B } & 20 \mathrm{~g} \\ \text { Lead oxide } & 75 \mathrm{mg} \\ \text { Congo red } & 75 \mathrm{mg} \\ \text { Eosin Y } & 0.38 \mathrm{mg} \\ \text { Gelatin } & \end{array}$

All liquid components were mixed together, all solid elements were added to liquid after heating it to $60^{\circ} \mathrm{C}$. The fluid was mixed manually until homogeneous.

TABLE 2: Visualization patterns with different injection pressures

\begin{tabular}{lccl} 
Group & $\begin{array}{c}\text { Number of porcine fetuses } \\
(\mathbf{n = 3 7 )}\end{array}$ & $\begin{array}{c}\text { Injection pressure } \\
(\mathbf{m m H g})\end{array}$ & \multicolumn{1}{c}{ Visualization pattern } \\
A & 3 & $0-10$ & No visualization \\
B & 3 & $11-15$ & Aorta \\
C & 3 & $16-20$ & Aorta + iliacs \\
D & 5 & $21-30$ & Aorta + iliacs + carotids + \\
E & 12 & $31-35$ & Extr \\
F & 5 & $36-40$ & Extravasation (IC) \\
G & 4 & $41-45$ & Extravasation (IC+IP) \\
H & 2 & $46-50$ & Extravasation \\
& & & $($ IC+IP+RP+Extr)
\end{tabular}

Extr Extremities; IC Intracranial; IP Intraperitoneal; RP Retroperitoneal

Guinea pig fetuses were obtained at 55 days' gestation from a breeding colony at The University of Texas Southwestern Medical Center, Dallas, Texas, and were surgically removed from the mother after long term (greater than 30 mins) halothane anesthesia of the mother to anesthetize the fetuses adequately. 


\section{RESULTS}

No visible perfusion was seen at injection pressures of less than $10 \mathrm{mmHg}$, and in general extravasation was first seen at an injection pressure of greater than $30 \mathrm{mmHg}$, although at times intracranial extravasation occurred at $25 \mathrm{mmHg}$.

Perfusion patterns at different anatomical sites were also influenced by different injection pressures. As the injection pressure was increased, sequential vascular zones appeared in the aorta, iliacs, carotids and extremities (Figure 1). Slightly higher pressure definitely caused extravasation intracranially, but may be necessary to resolve fine detail in the extremities (Figure 2). As the injection pressure exceeded $40 \mathrm{mmHg}$, vascular extravasation occurred in a sequential manner, from intracranial to intraperitoneal to pericardial to general at $50 \mathrm{mmHg}$ (Figures 3,4). In all cases studied, similar pressures induced similar extravasations, even comparing litter with litter.

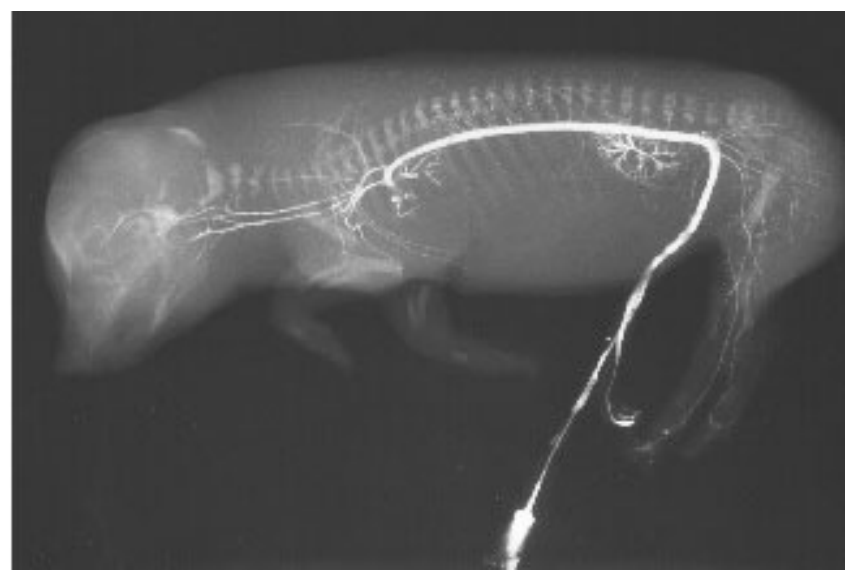

Figure 1) Radiograph of pig fetus perfused at 21 to $30 \mathrm{mmHg}$

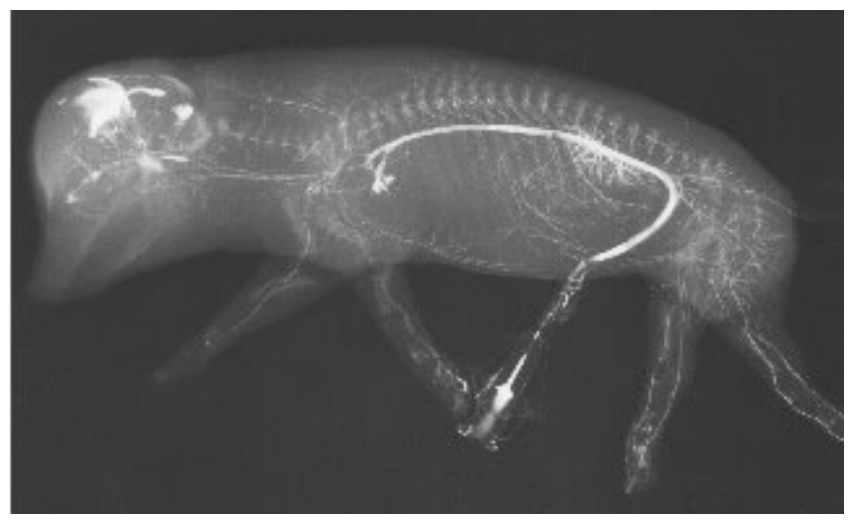

Figure 2) Radiograph of pig fetus perfused at 31 to $35 \mathrm{mmHg}$ 


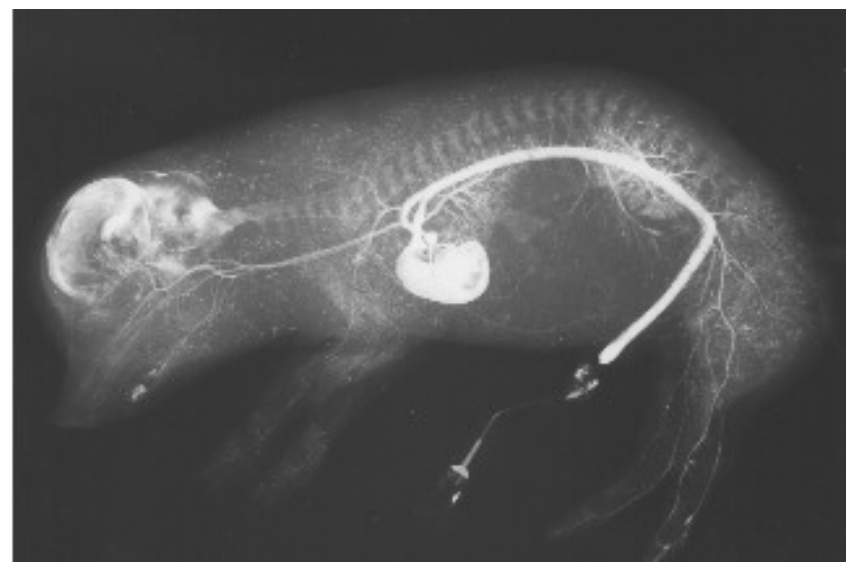

Figure 3) Radiograph of pig fetus perfused at 36 to $40 \mathrm{mmHg}$

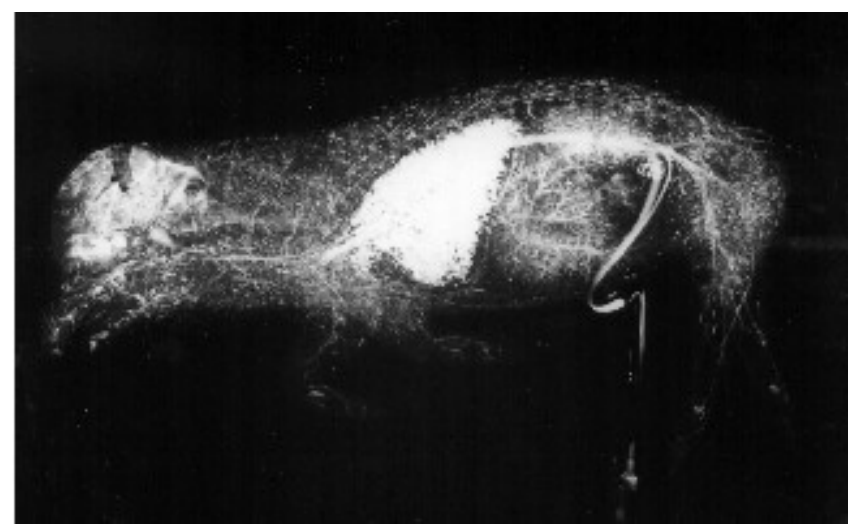

Figure 4) Radiograph of pig fetus perfused at 41 to $45 \mathrm{mmHg}$

To demonstrate overall applicability and test another system, guinea pig fetuses were also perfused at $30 \mathrm{mmHg}$. Results can be seen in Figures 5 and 6 . The slight fogging intracranially is the beginning of some extravasation.

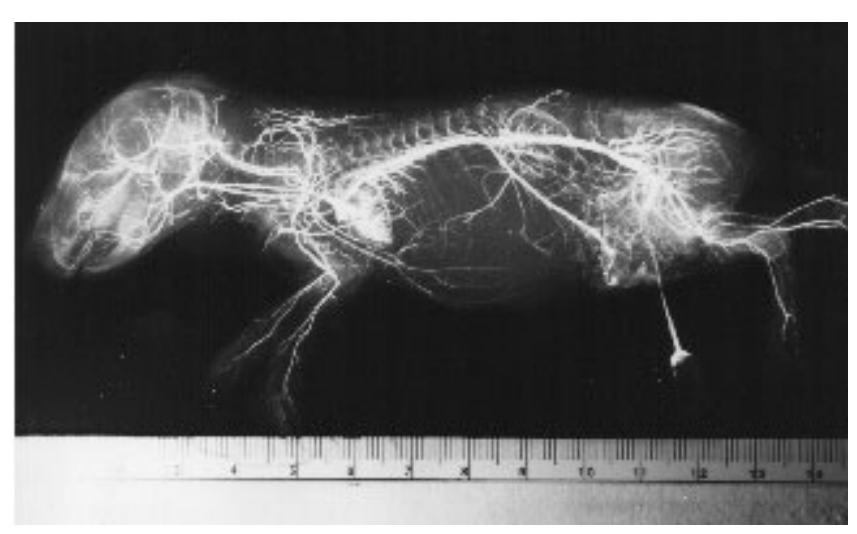

Figure 5) Radiograph of guinea pig fetus perfused at $30 \mathrm{mmHg}$ (lateral view) 


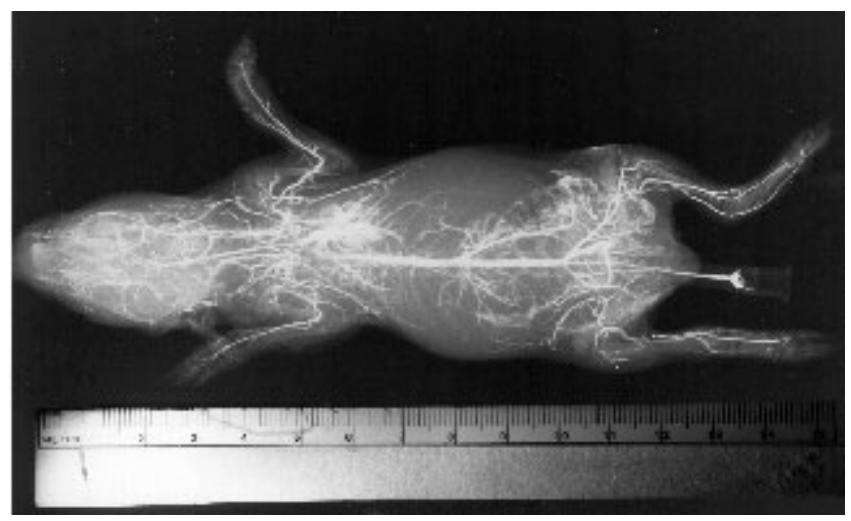

Figure 6) Radiograph of guinea pig fetus perfused at $30 \mathrm{mmHg}$ (anterior-posterior view)

\section{DISCUSSION}

As the search for a basis for birth defects continues, the question of linking the cause of a dysfunction to vascular defects requires careful planning. Because of the small size of most blood vessels, the dissection of fetal vasculature is a challenge, and a reliable method by which the vasculature can be seen postmortem is needed. While vascular perfusions in adults have been done for many years (13), the extreme delicacy of most fetal vascular elements cannot stand the 100 to $150 \mathrm{mmHg}$ pressure used in other perfusion systems. In this study we show that by controlling the pressure of perfusion and diluting the reagent to an appropriate specific gravity reproducible and accurate perfusion results can be obtained.

Increased use of maternal serum alpha-fetoprotein testing and improvement in ultrasound technology in recent years has resulted in the diagnosis of many disorders for which prenatal surgical reconstruction may improve (or allow) postnatal life (14-16). However, the morbidity and mortality associated with such in utero operative correction is a major concern (17-22). Precise monitoring of maternal and fetal pressures is an important element in reducing operative risks associated with fetal corrective surgery. To lessen the risks of fetal surgery, one must be familiar not only with the fetal vascular anatomy, but also with the pressure limitations of the fetal cardiovascular system $(23,24)$.

Results of this study give a better understanding of the fragility and pressure limitations of the fetal cardiovascular system (25-27). Minimal injection pressure of 10 $\mathrm{mmHg}$ resulted in minimal arterial visualization. Injection pressure of more than 30 $\mathrm{mmHg}$ created arterial contrast extravasation - a vascular perforation. Vascular visualization without extravasation was obtained with $10 \mathrm{mmHg}$ to $30 \mathrm{mmHg}$ of injection pressure.

Sequential arterial visualizations also have been determined. Aortic visualization was seen at a lower pressure (eg, $10 \mathrm{mmHg}$ ) followed by iliacs, carotids and finally extremities at a higher pressure (eg, $30 \mathrm{mmHg}$ ). Knowledge of the pressure limitations associated with fetuses allows the study of fetal vascular anatomy, especially of changes occurring as gestation progresses, a necessity for appropriate and informed design of fetal surgical procedures. Further studies are being done on human fetuses and at other times 
of gestations in the animal system to enhance understanding in this vital area and to improve fetal and maternal safety during intrauterine fetal surgery.

ACKNOWLEDGEMENTS: The authors acknowledge the technical support of Debby Noble and Christopher Gregory.

\section{REFERENCES}

1. Navaratnam V. Organization and reorganization of blood vessels in embryonic development. Eye 1991;5:147-50.

2. Parke WW. Photographic Atlas of Fetal Anatomy. Baltimore: University Park Press, 1975.

3. Harrison MR, Adzick NS. The fetus as a patient. Ann Surg 1991;213:279-91.

4. Arnold-Aidea SA, Parer JT. Fetal-maternal circulation in abnormal fetal growth. In: Divon MY, ed. Abnormal Fetal Growth. New York: Elsevier, 1991.

5. Patterson RM. Definition, epidemiology and morphometric classification of intrauterine growth retardation in abnormal fetal growth. In: Divon MY, ed. Abnormal Fetal Growth. New York: Elsevier, 1991.

6. Adamsons K, Muller-Heubach E, Myers RIE. Production of fetal asphyxia in the rhesus monkey by administration of catecholamines to the mother. Am J Obstet Gynecol 1971;109:248-62.

7. Beard RW. Response of human fetal heart and maternal circulation to adrenaline and noradrenaline. BMJ 1962;i:443.

8. Millicovsky G, DeSesso JM. Differential embryonic cardiovascular responses to acute maternal uterine ischemia; an in vivo microscopic study of rabbit embryos with either intact or clamped umbilical cords. Teratology 1980;22:335-43.

9. Barr M, Brent RL. Uterine vascular interruption and combined radiation and surgical procedure. Handbook in Teratology. New York: Plenum Press, 1978;4:275.

10. Buelke JS, Holsom JF. Distribution of maternal blood flow throughout gestation in the rat. Teratology 1980;21:2.

11. Potter EL, Craig JM. Pathology of the Fetus and the Infant. Chicago: Year Book Medical Publishers, 1975.

12. Rajaia GM, Kaplan S. Abnormally elevated blood pressure in trypan blue-treated chick embryos during early morphogenesis. Teratology 1980;21:247-51.

13. Peden EK, Robinson JB Jr, Rohrich RJ. An improved injection system for vascular anatomic studies having dual radiopacity and visualization capabilities. Ann Plast Surg 1994;32:407-10.

14. Drugan A, Timor-Tritsch IE. Transvaginal ultrasonography. In: Evans MI, Fletcher JC, Dixier AO, et al. Fetal Diagnosis and Therapy. Science, Ethics and the Law.

Philadelphia: JB Lippincott, 1989.

15. Asensio SH, Figueroa-Longo JG, Pelegrina IA. Intrauterine exchange transfusion. A new technique. Obstet Gynecol 1968;32:350-5. 
16. Gembruch U, Hansmann M. Artificial instillation of amniotic fluid as a new technique for the diagnostic evaluation of cases of oligohydramnios. Prenat Diagn 1988;8:33-45.

17. Pringle KC. Fetal surgery: It has a past, has it a future? Fetal Ther 1986;1:2331.

18. Harman CR. Bioethical issues in perinatology - is the future now? Fetal Ther 1986;1:217-22.

19. Lehmann DK, Mabie WC, Pernoll MI. The epidemiology and pathology of maternal mortality: Charity hospital of Louisiana in

New Orleans. Obstet Gynecol 1987;69:833-40.

20. Cochrane D, Coupland S. The feasibility of evoked potential monitoring in a fetal lamb model - An electro-physiological parameter of brain development. Fifth meeting of International Fetal Medicine and Surgery Society (IFMSS). Bonn: 1988.

21. Segal SS. Disorders of Galactose Metabolism and Metabolic Basis of Inherited Disease, 5th edn. New York: McGraw Hill, 1983.

22. Adzick NS, Vacanti JP, Lillehei CW. Fetal diaphragmatic hernia ultrasound diagnosis and clinical outcome in 38 cases from a single medical center. J Pediatr Surg 1990;24:654-7.

23. Harrison MR, Jester JA, Ross NA. Correction of congenital diaphragmatic hernia in utero. 1. The model: Intrathoracic balloon produces fatal pulmonary hypoplasia. Surgery $1980 ; 88: 174-82$.

24. Harrison MR, Bressack MA, Chung AM. Correction of congenital diaphragmatic hernia in utero. Simulated correction permits fetal lung growth with survival at birth. Surgery 1980;88:260-8.

25. Padget DH. The development of the cranial arteries in the human embryo. Contrib Embryo Carnegie Inst 1948;32:207.

26. Matsunaga E, Shiola K. Ectopic pregnancy and myoma uteri: Teratogenic effects and maternal characteristic. Teratology 1980;21:61-9.

27. Harrison MR, Globus MS, Filly RA. Management of the fetus with a correctable congenital defect. JAMA 1981;246:774-7. 